\title{
Pandemias e epidemias em perspectiva histórica: uma introdução
}

Gilberto Hochman*

Anne-Emanuelle Birn**

\section{RESUMO}

$\mathrm{O}$ artigo apresenta as principais questôes e os desafios da história e dos historiadores na análise das epidemias e pandemias. Aborda a importância da produção histórica brasileira e latino-americana nesse campo para a compreensáo das epidemias como fenômenos globais e suas tendências atuais. Discute a pandemia de COVID-19 na geraçáo de demandas crescentes por análises históricas das epidemias do passado e conclui apresentando os artigos do dossiê.

Palavras-chave: COVID-19; história; saúde; doença; América Latina; desigualdade.

\section{Pandemics and epidemics in historical perspective: an introduction}

\section{ABSTRACT}

This article discusses major issues and challenges faced by historians in analyzing epidemics and pandemics. It addresses the importance of Brazilian and Latin American historical production in understanding epidemics as global phenomena and outlines their current trends. It then discusses how the COVID-19 pandemic has generated a growing interest in historical analysis of past epidemics, and concludes by presenting the articles in the dossier. Keywords: COVID-19; history; health; disease; Latin America; inequality.

DOI: http://dx.doi.org/10.1590/2237-101X02204801

Artigo recebido em 23 de agosto de 2021 e aceito para publicação em 23 de setembro de 2021.

* Professor do Programa de Pós-Graduação em História das Ciências e da Saúde da Fundação Oswaldo Cruz, Rio de Janeiro/RJ, Brasil. E-mail: gilberto.hochman@fiocruz.br. ORCID: https://orcid.org/00000001-7834-336X.

** Professora da Dalla Lana School of Public Health, University of Toronto, Toronto, Canadá. E-mail: ae.birn@utoronto.ca. ORCID: https://orcid.org/0000-0002-0314-5913. 


\section{Pandemias y epidemias en perspectiva histórica: una introducción}

\section{RESUMEN}

El artículo presenta los principales problemas y retos de la historia y los historiadores en el análisis de epidemias y pandemias. Aborda la importancia de la producción histórica brasileńa y latinoamericana en este campo para entender las epidemias como fenómenos globales y sus tendencias actuales. Discute cómo la pandemia de COVID-19 ha generado una creciente demanda por el análisis histórico de epidemias pasadas y presenta los artículos en el dossier.

Palabras clave: COVID-19; historia; salud; enfermedad; América Latina; desigualdad.

Em Memórias Póstumas de Brás Cubas, de Machado de Assis, o narrador registra sua perplexidade e sofrimento contido pela morte de sua pretendente. Esta, entre muitas mortes, fora causada pela chegada e instalação da febre amarela na cidade do Rio de Janeiro, capital do Império, na segunda metade do século XIX:

[...] doeu-me um pouco a cegueira da epidemia que, matando à direita e à esquerda, levou também uma jovem dama que tinha de ser minha mulher; não cheguei a entender a necessidade da epidemia, menos ainda daquela morte. Creio até que esta me pareceu ainda mais absurda que todas as outras mortes (ASSIS, 1881, cap. 126 - Desconsolação, p.327-328.).

Há inúmeras passagens na literatura brasileira sobre epidemias, especialmente a febre amarela, a varíola, a gripe espanhola e, mais recentemente HIV-Aids, seja como pano de fundo e contexto, seja quase como um personagem. De Machado de Assis a Caio Fernando de Abreu, passando por João do Rio, Erico Verissimo e Pedro Nava, entre muitos outros, epidemias e pandemias estão presentes nas várias expressôes da cultura brasileira e latino-americana. Resultam de experiências que, ao mesmo tempo, são individuais e coletivas, subjetivas e realistas, singulares e universais que têm sido crescentemente escrutinadas por historiadores e historiadoras, especialmente diante da mesma perplexidade produzida pela pandemia de COVID-19.

A partir da década de 1990, na América Latina e, particularmente, no Brasil, a história da saúde, da doença, da medicina e das ciências biomédicas se integrou ao campo mais amplo da história, forjando novas agendas de pesquisa e novas compreensões. A história das epidemias implicou, por exemplo, o reconhecimento da inserção das dinâmicas locais e nacionais aos circuitos regionais e globais nas análises históricas sobre saúde e ciência e foi um elemento de renovação intelectual do próprio campo da história que produziu diálogos com inúmeras outras áreas como a saúde pública. A agência da América Latina tem sido uma das 
novidades nas leituras sobre a conformação da saúde internacional no século XX, desafiando visões correntes que, ainda que politicamente solidárias à região, reproduzem o que Birn denomina de "history-telling injustice", que desconsidera seu protagonismo, suas inovaçóes e produção de conhecimento (BIRN, 2020).

As transformaçôes políticas, culturais e sociais corridas na segunda metade do século XX modificaram o campo acadêmico da história com a incorporação de objetos como saúde e doença, mas também no modo pelo qual compreendemos as relações entre sociedade, medicina, saúde e doença. Dessa maneira, e a partir da emergência da pandemia de HIV-Aids na década de 1980, que abalou o otimismo sanitário do pós-Segunda Guerra, epidemias têm sido objetos cada vez mais frequentados por historiadores de diferentes posturas metodológicas e filiaçóes teóricas localizados em múltiplas instituições e países. São incontáveis os artigos, capítulos e livros sobre epidemias e pandemias. Todavia essa produção acadêmica norte-americana e europeia, ainda que renovada e atenta para a interpenetração de fenômenos biológicos e sociais, manteve suas preocupações e análises totalmente voltadas para os países do "Norte Global", por vezes tratando outras regióes ao sul com irrelevância, curiosidade ou mesmo com um humanitarismo benevolente.

Felizmente, o crescimento nas últimas décadas de trabalhos históricos sobre epidemias na América Latina e em outras partes do Sul Global evidencia que existem narrativas literárias e históricas alternativas para enquadrar as experiências da COVID-19 fora dos países de alta renda. Esses trabalhos têm buscado corrigir as desigualdades histórico-cognitivas e trazer temas e vozes menos visíveis e audíveis para o primeiro plano. Desse modo, desafiam o domínio hegemônico de narrativas sobre a vida durante as pandemias que, muito inspiradas recorrentemente na dramaturgia universalizadora, humanizadora e unificadora de $A$ peste de Albert Camus (1947), encobrem experiências marcadas por desunião, violência, iniquidades crescentes dentro e entre países e trajetórias e histórias diversas e imprevisíveis (KABEL; PHILLIPSON, 2020). Nesse sentido, a dramaturgia contra-hegemônica está, por exemplo, em "A peste", conto de João do Rio publicado em 1910 sobre uma epidemia de varíola na cidade do Rio de Janeiro durante a qual, além do contexto local, a humanidade dos personagens não é necessariamente edificante e nem há um final apaziguador.

Na produção sobre a América Latina, atenção tem sido dada às epidemias que estiveram associadas às sociedades de economias extrativistas, escravistas, agrário-exportadoras e dependentes ao longo do século XIX e primeira metade do século XX. ${ }^{1}$ Essas epidemias foram parte da conformação de instituiçóes públicas e comunidades científicas, médicas e de saúde pública, assim como mobilizaram organizaçóes internacionais e açóes filantrópicas e provocaram os debates sobre os rumos dos países no período pós-independências e pós-emancipação dos escravizados: cólera, peste bubônica, febre amarela, varíola e influenza. Tem crescido a produção no campo da história sobre essas manifestaçóes epidêmicas e pan-

${ }^{1}$ Um dos livros pioneiros é o de Chalhoub (1996). 
dêmicas nos países latino-americanos e caribenhos que, dada a natureza multifacetada e transnacional do fenômeno, combinam suas dimensóes locais e mundiais. Essa literatura tem refletido, para além do impacto social, econômico, político e cultural das epidemias/ pandemias, sobre as relaçóes entre as epidemias e meio ambiente, entre doenças e crise climática, sobre concepções de raça e etnicidade, sobre o racismo e sobre a desigualdade de gênero em contextos epidêmicos e sobre como a circulação de conhecimento e (des)informação incide sobre ideias, respostas e políticas domésticas. Essa produção tem sido referenciada em balanços relativos aos temas da história da saúde, da doença, das epidemias e da medicina na América Latina e no Caribe (ARMUS; LÓPEZ DENIS, 2011; BIRN; NECOCHEA, 2011; HOCHMAN; DI LISCIA; PALMER, 2012; ESPINOSA, 2013; CUETO; PALMER, 2016; HOCHMAN; TEIXEIRA; PIMENTA, 2018; CUETO; PALMER, 2019; CUETO, 2020; RAMOS, 2021; PORCELAIN, 2021).

A partir de março de 2020, com a pandemia de COVID-19, historiadores têm sido, mais do que nunca, convocados a se pronunciar sobre a emergência sanitária global. E não apenas historiadores, os jornalistas têm reiteradamente utilizado exemplos históricos ao escreverem e comentarem a pandemia. A história náo tem sido monopólio dos historiadores e, para além de uma infodemia, vivenciamos o que Anne-Emanuelle Birn denomina de historiodemia (BIRN, 2020, p. 336). As razões para tal são variadas. Todavia, a mais constante é a busca do conhecimento do passado para nos esclarecer sobre esse vertiginoso presente que é a experiência pandêmica e até mesmo prever o seu fim em um futuro que se deseja próximo.

Os movimentos globais de negaçáo da ciência e da própria pandemia têm afinidades e alinhamentos, por exemplo, com o negacionismo e revisionismo históricos, em especial em relação à escravidão, ao holocausto e aos regimes ditatoriais, demandando de historiadores e historiadoras mais intervençôes nos espaços públicos. Independentemente se há ou náo liçóes da história, os efeitos catastróficos do SARS-CoV-2 sobre os países do chamado Sul Global exigem uma reflexão acadêmica, ética e política dos historiadores e um diálogo mais ativo com a sociedade. $\mathrm{O}$ reconhecimento da complexidade do passado náo pode ser paralisante, assim como devem-se evitar as liçôes superficiais motivadas pelo momentâneo fascínio com a história. A impossibilidade de populaçôes e de continentes inteiros de terem acesso a recursos financeiros, medicamentos, equipamentos e vacinas indica que, se a emergência sanitária é global, os seus impactos são profundamente desiguais. Assim como desproporcional é o impacto da pandemia sobre mulheres, afrodescendentes, populações rurais, LGBTQIA+ e indígenas. Não menos importante é a existência de sistemas e serviços públicos de saúde capazes de lidar com emergências sanitárias e a presença de políticas e instituiçôes para o desenvolvimento científico e tecnológico. $\mathrm{O}$ ataque sistemático à ciência $\mathrm{e}$ aos cientistas, às organizaçóes internacionais e a política de desinformação operada por movimentos e governos de extrema direita são açóes que dificultam as respostas públicas e da sociedade, reproduzindo iniquidades. Dimensôes e efeitos desse processo têm sido realçados 
nos estudos históricos sobre as epidemias e pandemias: exclusão e desigualdades, assimetrias de informação e de poder em níveis locais, regionais e globais que trazem as marcas do colonialismo, do imperialismo e do racismo.

Historiadores têm sustentado que epidemias são, ao mesmo tempo, fenômenos biológicos e sociais. São processos sociais irredutíveis a uma história de fenômenos naturais e que articulam inexoravelmente patógenos, seres humanos e meio ambiente no tempo e no espaço. Historiadores também têm sido instados a debater como e quando o término de uma pandemia pode ser estabelecido à luz de experiências históricas. Se doenças e epidemias não são fenômenos estritamente biológicos, o fim da pandemia certamente não é determinado apenas pela existência de uma vacina e da vacinação em massa, de uma solução terapêutica eficaz, da queda da taxa de contágio, da obtenção da imunidade natural da populaçáo ou da diminuição dos registros de casos e dos óbitos. Isso se dá também pela forma como sociedades percebem a experiência epidêmica no presente, como partilham a memória das epidemias passadas, como compreendem e imaginam que a vida social, por elas interrompida, foi ou será reestabelecida e pelos interesses políticos e econômicos envolvidos nesse término. A convivência com ciclos epidêmicos, eventualmente mais brandos ou controláveis, ou com a endemicidade da doença, também é uma forma de selar o seu final (GREENE; VARGHA, 2020; HOCHMAN, 2021).

Epidemias, por serem eventos desorganizadores e trágicos, permitem desvelar e compreender as múltiplas faces de sociedades, em geral profundamente hierárquicas, injustas e desiguais. Elas possibilitam a análise das contingências, da pluralidade de possibilidades e dos interesses, da diversidade de escolhas possíveis dos indivíduos históricos, e das transformaçôes e dúvidas permanentes da própria vida social. Revelam as próprias incertezas do conhecimento científico e biomédico, e por que não dizer, dos cientistas e médicos que, em uma situação muito instável, são obrigados a disputar mais ainda a compreensão do fenômeno, o aconselhamento da população e das autoridades e o cuidado dos enfermos com outros atores sociais. Ainda que possam ser conjunturalmente fragilizadas, as relaçóes entre medicina e poder são reafirmadas nesses processos, muitas vezes criando novas hierarquias e subordinaçôes.

Um dos temas presentes são as formas pelas quais sociedades e governos respondem às crises produzidas pelas epidemias e às demandas por proteger os sãos, tratar dos doentes, controlar as populaçóes e velar os mortos. A história das epidemias e pandemias ainda demanda análises mais críticas sobre as razóes e os modos pelos quais diferentes sociedades relembram suas crises epidêmicas, ou as apagam de suas memórias. Essas análises, em geral, problematizam pouco a ideia de "epidemia esquecida" formulada por Crosby (2003) sobre a pandemia de 1918 nos EUA. Mais do que um recurso narrativo, o esquecimento denota relaçóes com um passado incômodo, com as avaliaçóes sobre omissóes e decisóes tomadas e os seus efeitos díspares em termos de classes sociais e, como a pandemia de COVID-19 
tem particularmente evidenciado, de gênero e raça (WAILOO, 2020). Mais do que locais, regionais ou nacionais, são eventos potencialmente globais que amplificam o sentimento de interdependência e de ameaça, seja real ou imaginária, e demandam a reflexão sobre as relações entre regiôes e países e as possibilidades e os limites da cooperação e da coordenação internacional para controlá-las.

A pandemia da gripe espanhola foi o evento histórico mais evocado, discutido e relembrado na pandemia de COVID-19. ${ }^{2}$ Crescentemente tem se perguntado também sobre as ondas pandêmicas de peste, de cólera no século XIX, ou mesmo sobre a gripe asiática (1957), a gripe de Hong Kong (1968), SARS (2003) e a gripe suína (2009) (HONIGSBAUM, 2020; PECKHAM, 2020; SIVARAMAKRISHNAN, 2020; HOCHMAN, 2021), todas com alcance global e mais recentes historicamente. Entretanto ainda está ausente um diálogo com a pandemia de HIV-Aids, bastante escrutinada por historiadores desde os anos 1980. Dada a extensa produção bibliográfica sobre as experiências nacionais e locais da influenza de 1918, e as narrativas de seu caráter devastador, historiadores foram perguntados sobre as semelhanças e diferenças de um presente igualmente devastador em relação ao passado. ${ }^{3}$ Essas perguntas têm sido um modo de buscar estabilizar a compreensáo frente às imensas incertezas de 2020 em relação ao conhecimento sobre o modo de transmissão e sobre o tratamento, às diferentes respostas das autoridades públicas, ao papel da imprensa, às disputas e ofertas de cuidados, terapias e curas, ao papel dos médicos e de outros profissionais de saúde como os farmacêuticos e enfermeiras, às instituiçôes assistenciais, à desconfiança e à culpabilização "do outro" e do estrangeiro. Está presente o debate sobre isolamento, quarentena e uso de máscaras e sobre a circulação de notícias e informação falsas. $O$ início da vacinação contra a COVID-19 no final de 2020 e início de 2021 mobilizou historiadores para falarem e escreverem sobre campanhas de imunização, resistência e hesitação vacinal, antivacinismo, tecnologias biomédicas, indústria farmacêutica, as (im)possibilidades de equidade no acesso às vacinas e o papel de organismos internacionais tais como a Organização Mundial da Saúde (OMS) e da filantropia global, cujo ator principal é a Fundação Gates. As perguntas se deslocaram para experiências bem-sucedidas de campanhas de vacinação em massa que levaram à erradicação da varíola no mundo ou contra a poliomielite, em vias de erradicação, e possíveis explicaçóes para as grandes diferenças de adesão às vacinas, por exemplo entre países latino-americanos, europeus e os Estados Unidos.

A pandemia de COVID-19 e a demanda por "mais história" motivou uma explosão de publicações de livros instantâneos, seminários, entrevistas, artigos, lives, podcasts e muitos dossiês temáticos em periódicos científicos de história e ciências sociais no Brasil, na Amé-

\footnotetext{
${ }^{2}$ É vasta a bibliografia sobre a pandemia de gripe espanhola. No Brasil destaco Britto (1997), Bertolli Filho (2003), Bertucci (2004), Goulart (2005), Silveira (2007), Souza (2009) e, numa perspectiva internacional e mais diversa, Porras-Gallo e Davis (2014).

${ }^{3}$ O livro de Schwarcz e Starling (2020) propóe um diálogo mais explícito entre a gripe espanhola e a COVID-19, assim como o de Carbonetti e Rivero (2020) sobre a gripe espanhola na Argentina.
} 
rica Latina, nos EUA, Canadá e na Europa. ${ }^{4}$ Dada a aceleração do tempo promovida pela pandemia, muito foi publicado, mas efetivamente poucas novidades surgiram em termos de pesquisa no campo da história das epidemias e das pandemias. Todavia, o mundo que foi reapresentado aos historiadores pela COVID-19 interpelou seu papel na comunicação pública da ciência, suas leituras e interpretaçóes sobre um passado que se transforma a partir de um presente marcado por 247 milhóes de casos e mais de 5 milhóes de mortos em outubro de 2021. O desafio atual é de "como ter uma teoria em meio a uma epidemia", que Paula Treichler enunciou em seu ensaio sobre Aids e foi atualizado nos tempos da COVID-19 (TREICHLER, 1999).

Os sete artigos que compóem o dossiê "Pandemias e epidemias em perspectiva histórica”, neste número da Topoi - Revista de História, apresentam resultados de pesquisas e reflexóes bastante originais que abordam múltiplos aspectos da história das epidemias no Brasil e na América Latina e estão marcados por uma diversidade regional, institucional e de gênero, assim como pela pluralidade de temas e abordagens. $\mathrm{O}$ dossiê, em seu conjunto, ultrapassa o contexto em que foi imaginado e formulado, o da pandemia, $\mathrm{O}$ primeiro artigo, "História, historiadores e a pandemia de COVID-19", reúne nove historiadoras e historiadores de diversas nacionalidades e radicados em diferentes instituiçóes no Brasil, Chile, Colômbia, Cuba, Estados Unidos e Índia. O artigo organiza as suas reflexôes sobre o impacto da pandemia nas práticas historiadoras, em suas agendas de pesquisa, sobre o campo da história e sobre o papel ético e político do historiador. Em "Parca vida, grande morte: pandemias, epidemias e memória das imagens na Amazônia de finais do século XIX e inícios do século XX”, Aldrin Figueiredo, Moema de Bacelar Alves e Silvio Ferreira Rodrigues analisam doença e morte nas representaçôes artísticas em coleções de pintura em Belém do Pará, estabelecendo uma leitura transversal a partir de questóes impostas pela COVID-19 como recurso heurístico comparativo. Maria Silvia Di Liscia, em seu artigo "La viruela y las políticas de inmunización en Argentina en el largo plazo", discute a história da varíola na Argentina a partir de políticas públicas ao longo dos séculos XIX e XX, em particular o tema da produçáo da vacina, das campanhas de vacinação

\footnotetext{
${ }^{4}$ Alguns exemplos de dossiês e números especiais publicados em 2020 e 2021 com artigos sobre história das epidemias: Apuntes - Revista de Ciências Sociales (disponível em: http://revistas.up.edu.pe/index.php/ apuntes); Bulletin of History of Medicine (disponível em: https://muse.jhu.edu/issue/44144); Centaurus: An International Journal of the History of Science and its Cultural Aspects (disponível em: https://onlinelibrary.wiley. com/toc/16000498/2020/62/2); Contraponto (disponível em: https://revistas.ufpi.br/index.php/contraponto/ issue/view/625); Estudos Históricos (disponível em: https:/www.scielo.br/j/eh/i/2021.v34n73/); Journal of Global History (disponível em: https://www.cambridge.org/core/journals/journal-of-global-history/issue/26 43FE31B4D3807371A4583EB23107D5); Mundos do Trabalho (disponível em: https://periodicos.ufsc.br/ index.php/mundosdotrabalho/issue/view/2982); Revista Brasileira de História (disponível em: https://www. scielo.br/j/rbh/i/2021.v41n87/); Revista Ciencias de la Salud (disponível em: https://revistas.urosario.edu.co/ index.php/revsalud). O blog da revista História, Ciências, Saúde - Manguinhos publicou textos de análise e opinião de historiados ao longo dos anos de 2020-2021, depois republicados no periódico (disponível em: http://www.revistahcsm.coc.fiocruz.br/. Acesso em: 22 ago. 2021).
} 
e da erradicação da doença no país nos anos de 1960. Ricardo dos Santos Batista nos apresenta, em "Nós não compreendemos exatamente o que ela quis dizer com 'vômito negro"': Fundação Rockefeller, ciência e a epidemia de febre amarela de 1926", a conexão entre epidemias de febre amarela no Nordeste brasileiro, ações da Fundação Rockefeller e conhecimento científico na década de 1920 e seus impactos na saúde internacional. Em "A pandemia nas lives semanais: o uso de atenuadores na retórica anticrise de Jair Bolsonaro", Alexandre Santos de Moraes e Daniel Pinha Silva examinam os discursos do presidente brasileiro nos primeiros meses da pandemia do novo coronavírus em seu canal do YouTube. Analisam como o tratamento discursivo empregado pelo presidente foi baseado numa estratégia retórica que busca controlar os efeitos de sentido dos atos de linguagem. Em "'Onde as forças vivas do trabalho se ajuntam em desmedida': dinâmicas da reprodução do capital em São Paulo durante a epidemia de febre amarela", Monique Felix Borin aborda as interaçôes entre as epidemias, cortiços e habitaçôes populares, imigração e reprodução do capital na Sáo Paulo atingida pela febre amarela. Fecha o dossiê o artigo de Rosangela Ferreira Leite, intitulado "Roupas de segunda mão: consumo, doença e descarte (São Paulo, 1900-1914)", no qual analisa, a partir dos experimentos sobre infecção por febre amarela chefiados por Emílio Ribas em 1903, os medos e os usos que as pessoas fizeram das roupas de segunda mão e a expansão de uma cultura de consumo baseada no descarte na cidade de São Paulo nas primeiras décadas do século XX.

O dossiê "Pandemias e epidemias em perspectiva histórica" foi possível graças ao honroso convite do Conselho Editorial da Topoi - Revista de História e ao trabalho de sua editora-chefe, Luiza Larangeira da Silva Mello. Foi um processo intenso e colaborativo de 18 meses, entre a chamada de artigos e a publicação final, que envolveu editorias, alunas do PPGHIS/ UFRJ, autores e pareceristas. Agradecemos a todos e todas e dedicamos essa publicação aos que foram, direta ou indiretamente, afetados pela COVID-19 e pela incúria, incompetência e descaso de governos e de governantes e pela ganância do setor privado.

\section{Referências}

ARMUS, Diego; LÓPEZ DENIS, Adrián. Disease, medicine and health. In: MOYA, Jose C. (ed.). The Oxford Handbook of Latin American History. Oxford: Oxford University Press, 2011. p. 424-453. Disponível em: https://doi.org/10.1093/oxfordhb/9780195166217.013.0016. Acesso em: 30 jul. 2021.

ASSIS, Machado de. Memórias Póstumas de Brás Cubas. Rio de Janeiro: Tipografia Nacional, 1881. Disponível em: https://digital.bbm.usp.br/handle/bbm/4826. Acesso em: 30 jul. 2021. BERTOLLI FILHO C. Epidemia e sociedade. A gripe espanhola em São Paulo, 1918. São Paulo: Editora Paz e Terra, 2003. 
BERTUCCI, Liane M. Influenza, a medicina enferma: ciência e práticas de cura na época da gripe espanhola em São Paulo. Campinas: Editora Unicamp, 2004.

BIRN, Anne-Emanuelle. Perspectivizing pandemics: (how) do epidemic histories criss-cross contexts? Journal of Global History, v. 15, n. 3, p. 336-349, 2020. Disponível em: https:// doi.org/10.1017/S1740022820000327. Acesso em: 31 jul. 2021.

BIRN, Anne-Emanuelle. How to have narrative-flipping history in a pandemic: views of/ from Latin America. Centaurus: An International Journal of the History of Science and its Cultural Aspects, v. 62, n. 2, p. 354-369, 2020. Disponível em: https://onlinelibrary.wiley. com/doi/epdf/10.1111/1600-0498.12310. Acesso em: 5 ago. 2021.

BIRN, Anne-Emanuelle; NECOCHEA, Raúl. Footprints on the future: looking forward to Latin American medical history in the twenty-first century. Hispanic American Historical Review, v. 91, n. 3, p. 503-27, 2011. Disponível em: https://doi.org/10.1215/001821681300164. Acesso em: 6 ago. 2021.

BRITTO, Nara A. La dansarina: a gripe espanhola e o cotidiano na cidade do Rio de Janeiro. História, Ciências, Saúde-Manguinhos, v. 4, n. 1, p. 11-30, 1997. Disponível em: https://doi. org/10.1590/S0104-59701997000100002. Acesso em: 6 ago. 2021.

CARBONETTI, Adrián; RIVERO, María Dolores. Argentina en tiempos de pandemia: la gripe española de 1918-1919: leer el pasado para comprender el presente. Córdoba: Editorial de la Universidad Nacional de Córdoba, 2020.

CHALHOUB, Sidney. Cidade febril: cortiços e epidemias na Corte imperial. São Paulo: Companhia das Letras, 1996.

CROSBY, Alfred W. America's Forgotten Pandemic: the influenza of 1918. 2. ed. Cambridge: Cambridge University Press, 2003.

CUETO, Marcos. El regreso de las epidemias. Salud y sociedad en el Perú del siglo XX. 2. ed. Lima: Instituto de Estudios Peruanos, 2020.

CUETO, Marcos; PALMER, Steven. History of public health in Latin America. Oxford Research Encyclopedia of Global Public Health, 25 fev. 2019. Disponível em: https:// oxfordre.com/publichealth/view/10.1093/acrefore/9780190632366.001.0001/acrefore9780190632366-e-20. Acesso em: 22 ago. 2021.

CUETO, Marcos; PALMER, Steven. Medicina e saúde pública na América Latina: uma história. Rio de Janeiro: Editora Fiocruz, 2016.

ESPINOSA, Mariola. Revisiting "What is an epidemic?" in the time of COVID-19: lessons from the history of Latin American public health. Bulletin of the History of Medicine, v. 94, n. 4, p. 627-636, 2020. Disponível em: https://doi.org/10.1353/bhm.2020.0086. Acesso em: 5 ago. 2021.

GOULART, Adriana C. Revisitando a espanhola: a gripe pandêmica de 1918 no Rio de 
Janeiro. História, Ciências, Saúde-Manguinhos, v. 12, n. 1, p. 101-142, 2005. Disponível em: https://doi.org/10.1590/S0104-59702005000100006. Acesso em: 7 ago. 2021.

GREENE, Jeremy A.; VARGHA, Dora. Ends of epidemics. In: BRANDS, Hal; GAVIN, Francis J. (orgs.). COVID-19 and World Order: the future of conflict, competition, and cooperation. Baltimore: Johns Hopkins University Press, 2020. p. 23-39. Disponível em: https://doi.org/10.1353/book.77593. Acesso em: 7 ago. 2021.

HOCHMAN, Gilberto. "A gripe asiática vem aí!?”: crônica de uma pandemia antes de sua chegada (Brasil, 1957). Revista Ciencias de la Salud, v. 19 (especial), p. 1-22, 2021. Disponível em: https://doi.org/10.12804/revistas.urosario.edu.co/revsalud/a.10599. Acesso em: 8 ago. 2021.

HOCHMAN, Gilberto. Quando e como uma doença desaparece. A varíola e sua erradicação no Brasil, 1966/1973. Revista Brasileira de Sociologia, v. 9, p. 103-128, 2021.

HOCHMAN, Gilberto; TEIXEIRA, Luiz A.; PIMENTA, Tânia S. História da saúde no Brasil: uma breve história. In: TEIXEIRA, Luiz Antonio; PIMENTA, Tânia Salgado; HOCHMAN, Gilberto (orgs.). História da Saúde no Brasil. São Paulo: Hucitec Editora, 2018. p. 9-26.

HOCHMAN, Gilberto; DI LISCIA, Maria Silvia; PALMER, Steven. Patologías de la patria: una introducción al tema. In: HOCHMAN, Gilberto; DI LISCIA, Maria Silvia; PALMER, Steven (orgs.). Patologías de la patria: enfermedades, enfermos y nación en América Latina. Buenos Aires: Lugar Editorial, 2012. p. 13-27.

HONIGSBAUM, Mark. Revisiting the 1957 and 1968 influenza pandemics. Lancet, n. 395, p. 1.824-1.826, 2020. Disponível em: https://doi.org/10.1016/S0140-6736(20)31201-0. Acesso em: 5 ago. 2021.

KABEL, Ahmed; PHILLIPSON, Robert. Structural violence and hope in catastrophic times: from Camus' The Plague to COVID-19. Race \& Class, v. 62, n. 4, p. 3-18, 2021. Disponível em: https://doi.org/10.1177/0306396820974180. Acesso em: 3 ago. 2021.

PECKHAM, Robert. Viral Surveillance and the 1968 Hong Kong Flu Pandemic. Journal of Global History, v. 15, n. 3, p. 444-458, 2020. Disponível em: https://doi.org/10.1017/ S1740022820000224. Acesso em: 3 ago. 2021.

PORCELAIN, Sherri L. Public Health and Beyond in Latin America and the Caribbean: reflections from the field. Nova York: Routledge, 2021. Disponível em: https://doi. org/10.4324/9781003007401. Acesso em: 4 ago. 2021.

PORRAS-GALLO, Maria-Isabel; DAVIS, Ryan A. (orgs.). The Spanish Influenza Pandemic of 1918-19: perspectives from the Iberian peninsula and the Americas. Rochester: University of Rochester Press, 2014.

RAMOS, Christina. Beyond the Columbian Exchange: medicine and public health in 
colonial Latin America. History Compass, e12682, 2021. Disponível em: https://doi. org/10.1111/hic3.12682. Acesso em: 8 ago. 2021.

SCHWARCZ, Lilia M.; STARLING, Heloísa G. A bailarina da morte: a gripe espanhola no Brasil. São Paulo: Companhia das Letras, 2020.

SILVEIRA, Anny JT. A influenza espanhola numa capital planejada - Belo Horizonte, 1918. Belo Horizonte: Argvmentvm, 2007.

SIVARAMAKRISHNAN, Kavita. Endemic Risks: influenza pandemics, public health, and making self-reliant Indian citizens. Journal of Global History, v. 15, n. 3, p. 459-477, 2020. Disponível em: http://doi.org/10.1017/S1740022820000340. Acesso em: 4 ago. 2021.

SOUZA, Christiane MC. Gripe espanhola na Bahia - saúde, politica e medicina em tempos de epidemia. Rio de Janeiro: Editora Fiocruz, 2009. Disponível em: https://doi. org/10.7476/9788575415382. Acesso em: 6 ago. 2021.

TREISCHLER, Paula. How to Have Theory in an Epidemic: cultural chronicles of AIDS. Durham: Duke University Press, 1999.

WAILOO, Keith. Spectacles of difference: the racial scripting of epidemic disparities. Bulletin of the History of Medicine, v. 94, n. 4, p. 602-625, 2020. Disponível em: https://doi. org/10.1353/bhm.2020.0085. Acesso em: 5 ago. 2021. 